Enrico Gallazzi $\quad$ ORCID iD: 0000-0001-9287-9937

Alessandro Bidossi ORCID iD: 0000-0003-3141-8920

\title{
Title
}

\section{BACTERIAL ADHESION ON SPINAL IMPLANTS: AN IN VITRO STUDY OF "HOT SPOTS"}

\section{RUNNING HEAD}

\section{BACTERIAL ADHESION ON SPINAL IMPLANTS}

\section{Authors:}

Andrea Luca ${ }^{(1) *}$, MD, Enrico Gallazzi ${ }^{(1)^{*}}$, MD, Elena De Vecchi ${ }^{(2)}$, MSc, Marco Brayda-Bruno $^{(1)}$, MD, Alessio Lovi ${ }^{(1)}$, MD, Lisa Babbi ${ }^{(1)}$, MD, Giuseppe Maria Peretti ${ }^{(3)}$, FP, Alessandro Bidossi, $\mathrm{PhD}^{(2)}$

(1) Spine Unit III, IRCCS Orthopedic Institute Galeazzi, Milan, Italy

(2) Laboratory of Clinica Chemistry and Microbiology, IRCCS Orthopedic Institute Galeazzi

(3) Director of the Residency Program in Orthopaedics and Traumatology Department of Biomedical Sciences for Health

*These authors contributed equally to the manuscript.

Corresponding Author:

Andrea Luca

IRCCS Orthopedic Institute Galeazzi, Via R. Galeazzi 4, 20161 Milan, Italy

Email: aluca.md@gmail.com

Authors' Contribution Statement:

ALu and EG: Original Ideation of the Study. Implant preparation for the Experiment. Writing the Manuscript.

This article has been accepted for publication and undergone full peer review but has not been through the copyediting, typesetting, pagination and proofreading process, which may lead to differences between this version and the Version of Record. Please cite this article as doi: 10.1002/jor.24960. 
AB: Conducted the Experimental Part. Writing of the Manuscript

EDV: Coordinated the Experimental Part. Revised the Mansucript

ALo, LB, GMP and MBB: Critical Review of the Manuscript

All the authors have read and approved the final version of the Manuscript.

\section{ABSTRACT}

Few studies evaluated bacterial colonization of spinal implants from a "topographic" point of view. This lack of knowledge could hinder the development of more effective strategies in the prevention and treatment of postoperative spinal infections. The aim of this in vitro study was the analysis of the adhesion pattern of sessile cells on conventional spinal implants, in order to identify 'hot spots' on implants where bacterial adhesion could be favored. Clinically relevant Staphylococcus aureus, Staphylococcus epidermidis and Pseudomonas aeruginosa isolates were grown on commercially available end product spinal implants. To identify sessile cells attached to implant surfaces confocal laser scan microscopy was used. Different areas from the spinal instrumentations (both $\mathrm{Ti}$ and $\mathrm{CoCr}$ ) were selected for biofilm quantification. Bacterial biofilm was markedly increased in the cut of the rods, both $\mathrm{Ti}$ and $\mathrm{CoCr}$, as the uneven surface deriving from the cut might foster cell adhesion. Though not statistically significant, a difference was observed between the rod and the area of the notch, possibly as a consequence of the smoothening effect deriving from the bending of the rod. Finally, the amount of biofilm produced on cobalt-chromium surfaces was always more significant than that formed on titanium surfaces. This study highlights how bacterial adhesion through biofilm formation is favored on the surfaces of higher irregularity and that staphylococci are able to increase sessile biomass on $\mathrm{CoCr}$ surfaces. These preliminary results show how surface modifications on the implants 
may play a key role in bacterial adhesion, opening an exciting field for future research.

\section{INTRODUCTION}

Surgical site infections (SSIs) are one of the most challenging complications in spine surgery ${ }^{1}$. Their incidence is estimated between $2 \%$ and $13 \%$, with thoracolumbar surgery being at the higher end of the range ${ }^{2}$. These complications represent an enormous burden for patients, in terms of increased morbidity and even mortality, and for the national health systems, in terms of increased costs for medications and reoperations. However, relatively few studies have investigated the pathobiology of spinal SSIs.

Conversely, in the last decade, a considerable amount of studies clarified the critical role of bacterial biofilm formation on implants in SSIs: according to the model of the 'race for the surface', bacteria and host cells compete for adhering to implant surfaces. Bacterial cells would attach with a very low probability to the implant when the host cells colonize the implant surface first, and vice versa ${ }^{3}$. Implant surfaces, in particular those presenting increased roughness and large-scale irregularities, offer a perfect environment for the bacterial adhesion process. Once bacteria have adhered to the implant surface, cells start organizing in a biofilm by producing an extracellular, three-dimensional polymeric matrix composed of polysaccharides and proteins that encapsulate bacteria, effectively protecting them from the host's immune system aggression and antibiotics ${ }^{4}$.

While in other fields of orthopedics (i.e. arthroplasty) the role of biofilm is well established and its implications of recalcitrance to antibiotic treatment and immune system attack are taken in consideration for the treatment indications, very little is 
known concerning the behavior of biofilm in spinal instrumented surgery ${ }^{5,6}$. Moreover, despite material characteristics and shape are well known to influence biofilm formation ${ }^{7}$, very few data are available concerning bacterial adhesion on specific implants surfaces and materials or component features that could be more favorable for biofilm formation ${ }^{8,9}$. Knowing where biofilm develops on spinal implants could be critical in implementing effective strategies to prevent and treat spinal SSIs.

Given these premises, the aim of this study was the analysis of adhesion pattern of sessile cells on conventional spinal implants, in order to identify 'hot spots' on implants where bacterial adhesion could be favored.

\section{METHODS}

\section{Bacterial strains}

Clinically relevant strains isolated from spinal construct infections at the Laboratory of Clinical Chemistry and Microbiology of the IRCCS Galeazzi Orthopedic Institute were used. In particular, the following bacterial species were tested in the first part of this study: methicillin-resistant S. aureus (MRSA), methicillin-resistant S. epidermidis (MRSE) and Pseudomonas aeruginosa. Identification and antimicrobial susceptibility testing were carried out on a Vitek2 Compact (BioMerieux, Marcy L'Etoile, France). All strains were stored at $-80^{\circ} \mathrm{C}$ in proper broths enriched with $10 \%$ glycerol (VWR Chemicals, Leuven, Belgium) until used.

\section{Spinal constructs}

Commercially available spinal implant from two different manufacturers (DePuy

Spine, Johnson\&Johnson, New Brunswick, New Jersey, USA; Stryker K2M,

This article is protected by copyright. All rights reserved. 
Kalamazoo, Michigan, USA) were used for the in vitro analysis: in particular, two straight rods for each manufacturer, one in Cobalt Chromium $(\mathrm{CoCr})$ alloy and one in Titanium (Ti) alloy. Two different rod designs were studied: standard round rods (design 1) and omega-shaped rods (design 2). All the rod samples were cut in 5-7 cm pieces with the rod cutter (B. Braun Aesculap, Melsungen, Germany) and, once cut, the pieces were bent at a single point to create a bending notch with the French bender: both instruments are routinely used for surgeries. The bent rods were eventually connected to a screw of the same manufacturer and the head screw plugs were closed with the standard screwdriver included in the surgical set, thus obtaining a single rod single screw construct. For the analysis of the cut surface, the same rods were cut in $1 \mathrm{~cm}$ pieces, in order to fit in the confocal scan laser microscope (CLSM).

Before the experiments, all the instrumentations were immersed in absolute ethanol and washed with sterile distilled water. Subsequently, were put in plastic boxes and sterilized in autoclave. After sterilization, the boxes were opened under sterile hood and the kept in the boxes until use.

\section{In vitro biofilm formation on spinal constructs}

Rods, tulips and screws were put in a sterile specimen container and submerged with Brain Heart Infusion (BHI) broth (Biolife Italiana S.r.l. Milano, Italy). Bacterial strains grown overnight at $37^{\circ} \mathrm{C}$ in Tryptic Soy Agar (TSA, Biomérieux, Marci l'Etoile, France) were resuspended in sterile saline solution at a turbidity of $0,5 \mathrm{McF}$ (approximately $1.5 \times 10^{8} \mathrm{CFU} / \mathrm{ml}$ ), inoculated in the cups containing the spinal instrumentation to a final concentration of $1 \times 10^{7} \mathrm{CFU} / \mathrm{mL}$ and let them grow for $48 \mathrm{~h}$ to form a mature biofilm.

This article is protected by copyright. All rights reserved. 


\section{Confocal laser scan microscopy (CLSM) analysis of sessile cells}

After incubation, spinal implants were gently washed with sterile saline and stained with Syto ${ }^{\text {TM }} 9$ green fluorescent nucleic acid stain (Thermo Fisher Diagnostics SpA, Rodano, Italy). Briefly, the staining solution was prepared by adding $1 \mu \mathrm{L}$ of Syto ${ }^{\mathrm{TM}} 9$ to $1 \mathrm{~mL}$ of filter-sterilized water. Samples were stained by wetting the whole surfaces of the spinal implants with the staining solution three times during 15 minutes of incubation at room temperature in the dark. After incubation, samples were washed with sterile saline and directly examined with an upright TCS SP8 (Leica Microsystems CMS GmbH, Mannheim, Germany) using a 20× dry objective (HC PL FLUOTAR 20×/0.50 DRY). A $488 \mathrm{~nm}$ laser line was used to excite Syto ${ }^{\mathrm{TM}} 9$. Sequential optical sections of $1.27 \mu \mathrm{m}$ were collected along the $\mathrm{z}$-axis over the entire thickness of the sample. Images from at least three randomly selected areas were acquired for each surface of six independent replicas. The obtained images were processed with Las X software (Leica Microsystems CMS GmbH, Mannheim, Germany) and analyzed by Fiji software (Fiji, ImageJ, Wayne Rasband National Institutes of Health).

\section{Statistical analysis}

Comparisons among groups were analyzed by the Kruskal-Wallis test (GraphPad Prism v5.00 Software, USA) corrected with Dunnett's post hoc test. All data were expressed as median and interquartile ranges. Comparison between the two biomaterials was performed by means of two-way ANOVA, followed by Bonferroni post hoc correction. Values of $\mathrm{p}<0.05$ were considered as statistically significant.

This article is protected by copyright. All rights reserved. 


\section{RESULTS}

\section{Quantification of biofilm cells on spinal constructs surfaces}

Three different sampling areas were analyzed for each of the two rod's designs. The surface at the extremities, resulting from the cut of the rod, displayed a marked, statistically significant increase in bacterial attachment (for all the three tested species), with respect to all the other surfaces. This behavior could be observed in both designs and biomaterials (Fig 1, 2, 3, 4). With regard to the design 1, the two staphylococcal strains seemed to adhere less to the small notch area compared to the rod surface, even if this difference was not statistically significant (Fig 1a, 1b, 2a, 2b), while $P$. aeruginosa adhesion did not seem to be affected by the polished notch surface, resulting from the bending (Fig 3a, 3b). With regard to the design 2, none of the tested species displayed any difference between the flat and the round surface of the $\operatorname{rod}($ Fig 1c, 1d, 2c, 2d, 3c, 3d).

While S. aureus and S. epidermidis attached similarly to the rods surfaces of the two designs (Fig 5a, 5b), P. aeruginosa biofilm formation was significantly higher on the design 1 surface on both $\mathrm{Ti}$ and $\mathrm{CoCr}$ (Fig 5c). Furthermore, significant differences were observed between the two biomaterials. The higher biofilm formation was always observed on CoCr surfaces, mostly displayed by the two staphylococci (Table 1). In particular, these differences were mostly observed in the cut surfaces, which correlates the higher biofilm biomasses observed.

When comparing the two rod's designs to the tulips and screws surfaces, the most notable differences could be observed for the CoCr rods (Fig 5). It must be considered that both the tulips and the screws are made of titanium alloy, and it confirms a different microbial adhesion capability on the two alloys (Table 1).

This article is protected by copyright. All rights reserved. 


\section{DISCUSSION}

Surgical Site Infections are one of the most feared complications following spine surgery. Nonetheless, current research mainly focuses on gathering epidemiological data, risk factors evaluation and prevention strategies ${ }^{10-12}$, with very few studies focusing on the pathobiology of infections in this setting. The importance of biofilm in the development and maintenance of implant-related infections is well established, and its characteristics of persistence and recalcitrance explain the difficulties in treatment and eradication of infections ${ }^{13}$. According to this model, it seems that preventing bacterial colonization of implants could be the most effective prevention strategy for SSI. While several improvements were made concerning implant protection in prosthetic joint replacement ${ }^{14}$, those achievements cannot be readily applied to spine surgery: first, the microenvironment in which the 'extra-osseous' parts of the implants are, is different from the one of a prosthesis, i.e. the implants are surrounded by serum and not by synovial fluid; moreover, while hardware exchange is an accepted strategy for treating prosthetic joint infections, this cannot be similarly applied in spine surgery, where retention of hardware is required for spinal stability. Given these differences, it is crucial to identify the sites more prone to harbor bacterial colonies.

In order to better understand the behavior of biofilm on spinal implants, we designed an in vitro study aimed to map the area of the implants that favor bacterial overgrowth. Our methodology consisted of growing bacterial cells in the presence of the spinal implant, and then, identifying bacterial 'hot spots' with CLSM, i.e. the area of the implant where bacterial attachment and biofilm formation was favored.

This article is protected by copyright. All rights reserved. 
Our main findings concern either the rod design, the surface pattern and the alloy material. First, we observed that the increase in surface irregularity, such as at the cut of spinal rods, is one of the primary surface characteristics that favors biofilm formation. Second, regarding the implant materials, we found that $\mathrm{CoCr}$ rods seem to be more susceptible to bacterial adhesion than the $\mathrm{Ti}$ alloy rods, the tulip and the thread of the screws.

In this study, we have investigated four different surfaces: the thread of the screws, the rod surface, the rod cuts and notches. All these surfaces were susceptible to bacterial colonization. To the author's knowledge, this is the first study that reports topographic information on biofilm formation on spinal implants end-product.

At first, these findings suggest that surface finishing, and in particular surface roughness, could play an important role in favoring bacterial adhesion. Other in vitro studies have already highlighted that surface roughness is a crucial factor influencing biofilm formation ${ }^{15,16}$. A possible explanation is that roughness increases the available surface for bacterial adhesion, and that the smaller dimension of bacterial cells, when compared to fibroblasts and other host cells, could allow them to access surface areas inaccessible to host cells ${ }^{9}$. Surface smoothness to nanometric level was indeed found to be associated with the lowest adhesion rates both for Gram-positive and Gram-negative bacteria ${ }^{17}$. While for a bony implantable device roughness at a nanoscale is considered a positive characteristic since it increases osteoblast activity and therefore osteointegration ${ }^{18}$, for a surface that does not need to enter in direct contact with bone, such as the rods in spinal implant, it can only be a negative characteristic offering more harboring sites for bacteria. Interestingly, we commonly observed a slightly lower biofilm biomass on the notches produced by pressing the rod 
with the French bender, when compared to the rougher surfaces of the rod and the rod cut. This observation could be explained by the "satinized" surface of the rod, which might ease the bacterial adhesion with respect to the notch surface, which results smoothened when bent.

The second main finding of our study was that $\mathrm{CoCr}$ rods were associated with increased biofilm formation when compared to Ti alloy rods and screws. In a previous study performed in our laboratories investigating biofilm formation on Ti alloy and CoCr discs, either sandblasted or mirror polished, other clinical isolates of $S$. aureus and $P$. aeruginosa displayed a similar or higher adhesion and biofilm formation on CoCr surfaces ${ }^{19}$. Furthermore, these results are in accordance with another study by Patel et al., where machine-cut spinal rods of the same size were challenged for $S$. aureus biofilm formation. Colony-forming units count of the cells retrieved from the whole surface revealed that $\mathrm{CoCr}$ rods had a higher proclivity toward to bacterial sessile growth than titanium alloy ${ }^{20}$. In addition, in an in vivo animal model it was reported significantly lower biofilm cells on polished fixation plates, compared to those with satinized surface ${ }^{21}$. This is in line with the observations made in our study that report lower biomass adhering to the smoothest areas, i.e. the polished surface in the notch. Though these differences were not significant, we believe we could not appreciate it because of the extraordinary biofilm attachment that was observed on the uneven surfaces of the cuts. While we are not able to determine if there are differences in surface finishing between $\mathrm{Ti}$ and $\mathrm{CoCr}$ rods of the same design, we can assume that they might be similar as produced by the same manufacturer. This is a known limitation of our study for which additional surface analysis would be needed.

This article is protected by copyright. All rights reserved. 
Our study has some limitations. First of all, the in vitro setting does not consider all the physiological variables that might influence, positively or negatively, bacterial biofilm formation on implanted materials. Indeed, the immune system and systemic antibiotics can be of hindrance towards contaminating cells "racing for the surface". On the contrary, neutrophils are unable to phagocytize surface attached microcolonies exceeding $10 \mu \mathrm{m}$ of diameter ${ }^{22}$ and studies reported that mature biofilms exposed to sub-inhibitory concentrations on antibiotics were rapidly induced to increase the biomass, the antibiotic resistance and expression of extracellular polysaccharide ${ }^{23,24}$. While in vitro studies conducted in presence of synovial fluids revealed an altered biofilm formation on the underlying titanium surfaces, probably induced by host proteins ${ }^{25,26}$, preliminary studies in our lab doesn't support the same for serum (data not shown), which, on the contrary, doesn't promote sessile growth as much as synovial fluids or lab medium. However, this protocol was designed to easily map biofilm aggregates attached to those surfaces more susceptible to bacterial colonization. These results are meant to provide indications on the weaknesses of implant surfaces and in the future they will need a validation from in vivo analysis.

In our study, we employed only three species of biofilm producing-bacteria for our experimental settings ( $S$. aureus, S. epidermidis and $P$. aeruginosa). While this choice limits the application of our results to infections due to other species, it allowed us to get a more reproducible experimental design; moreover, we used three bacterial strains that were isolated from patients who were diagnosed with spinal SSI, in order to have an experimental setting as close as possible to the in vivo situation. Finally, the three specimens selected covers both the Gram positive and Gram negative groups, and taken together are responsible for more than the $60 \%$ of all SSI in spine surgery, according to recent epidemiological data ${ }^{12}$.

This article is protected by copyright. All rights reserved. 


\section{CONCLUSION}

To the best of the authors' knowledge, the present study is the first that evaluates the topography of biofilm formation on end-product spinal implants. Mapping the area of implants that favor biofilm formation could be useful both for optimizing implant design and in clinical practice. Concerning implant design, our data could provide relevant information on implant proprieties and surface characteristics that could eventually help to improve infection recalcitrance. In particular, mirror polished surfaces should be preferred when the device is not meant to be osteointegrated and macroscopic irregularities in the design should be avoided to minimize the probability of bacterial adhesion and biofilm maturation. In addition, a particular attention should be payed to modifications of the devices made in the operating room, such as the cut of the rods. Furthermore, if our data will be confirmed by in vivo retrieval studies, they could offer in clinical practice crucial information to focus on specific implant target area, when dealing with SSI. Overall, our preliminary results show how often neglected implant characteristics play a key role in bacterial adhesions and direct investigations of the implant's surfaces by means of microscopic analysis could further improve the knowledge of biofilm infections of medical devices.

\section{ACKNOWLEDGEMENT}

The authors want to Acknowledge the two Manufacturers that freely provided the spinal implant used for the test: DePuy Spine, Johnson\&Johnson, New Brunswick, New Jersey, USA and Stryker K2M, Kalamazoo, Michigan, USA

The manufacturers had no role in study design, data collection and analysis, decision to publish, or preparation of the manuscript. No benefits in any form have been or will 
be received from any commercial party related directly and indirectly to the subject of the article.

The Authors declare that they have no conflict of interests concerning the present paper.

\section{REFERENCES}

1. Bible JE, Biswas D, Devin CJ. Postoperative infections of the spine. Am J Orthop (Belle Mead NJ). 2011;40(12):E264-71.

2. McClelland S 3rd, Takemoto RC, Lonner BS, et al. Analysis of Postoperative Thoracolumbar Spine Infections in a Prospective Randomized Controlled Trial Using the Centers for Disease Control Surgical Site Infection Criteria. Int J spine Surg. 2016;10:14. doi:10.14444/3014

3. Gristina AG, Hobgood CD, Webb LX, Myrvik QN. Adhesive colonization of biomaterials and antibiotic resistance. Biomaterials. 1987;8(6):423-426. doi:10.1016/0142-9612(87)90077-9

4. McConoughey SJ, Howlin R, Granger JF, et al. Biofilms in periprosthetic orthopedic infections. Future Microbiol. 2014;9(8):987-1007. doi:10.2217/fmb.14.64

5. Hickok NJ. What are Biofilms? Spine (Phila Pa 1976). 2018;43(7):S7-S8. doi:10.1097/BRS.0000000000002548

6. Izakovicova $\mathrm{P}$, Borens $\mathrm{O}$, Trampuz A. Periprosthetic joint infection: current concepts and outlook. EFORT open Rev. 2019;4(7):482-494. doi:10.1302/20585241.4.180092

7. Romanò CL, Scarponi S, Gallazzi E, Romanò D, Drago L. Antibacterial coating of implants in orthopaedics and trauma: A classification proposal in an evolving panorama. J Orthop Surg Res. 2015;10(1):1-11. doi:10.1186/s13018015-0294-5

8. Swearingen MC, DiBartola AC, Dusane D, Granger J, Stoodley P. 16S rRNA analysis provides evidence of biofilms on all components of three infected periprosthetic knees including permanent braided suture. Pathog Dis. 2016;74(7). doi:10.1093/femspd/ftw083

9. Davidson DJ, Spratt D, Liddle AD. Implant materials and prosthetic joint infection: the battle with the biofilm. EFORT open Rev. 2019;4(11):633-639. doi:10.1302/2058-5241.4.180095

10. Aleem IS, Tan LA, Nassr A, Riew KD. Surgical Site Infection Prevention Following Spine Surgery. Glob spine J. 2020;10(1 Suppl):92S-98S. doi:10.1177/2192568219844228

This article is protected by copyright. All rights reserved. 
11. Nasser R, Kosty JA, Shah S, Wang J, Cheng J. Risk Factors and Prevention of Surgical Site Infections Following Spinal Procedures. Glob spine J. 2018;8(4 Suppl):44S-48S. doi:10.1177/2192568218806275

12. Shillingford JN, Laratta JL, Reddy H, et al. Postoperative Surgical Site Infection After Spine Surgery: An Update From the Scoliosis Research Society (SRS) Morbidity and Mortality Database. Spine Deform. 2018;6(6):634-643. doi:10.1016/j.jspd.2018.04.004

13. Arciola CR, Campoccia D, Montanaro L. Implant infections: adhesion, biofilm formation and immune evasion. Nat Rev Microbiol. 2018;16(7):397-409. doi:10.1038/s41579-018-0019-y

14. Romanò CL, Gallazzi E, Scarponi S, Morelli I, Drago L. Coating: Antibacterial Coating of Implants in Orthopaedics and Trauma.; 2017. doi:10.1007/978-3662-54469-3_9

15. Bacakova L, Filova E, Parizek M, Ruml T, Svorcik V. Modulation of cell adhesion, proliferation and differentiation on materials designed for body implants. Biotechnol Adv. 2011;29(6):739-767. doi:10.1016/j.biotechadv.2011.06.004

16. Lu T, Qiao Y, Liu X. Surface modification of biomaterials using plasma immersion ion implantation and deposition. Interface Focus. 2012;2(3):325336. doi:10.1098/rsfs.2012.0003

17. Mitik-Dineva N, Wang J, Truong VK, et al. Escherichia coli, Pseudomonas aeruginosa, and Staphylococcus aureus Attachment Patterns on Glass Surfaces with Nanoscale Roughness. Curr Microbiol. 2009;58(3):268-273. doi:10.1007/s00284-008-9320-8

18. Montanaro L, Campoccia D, Arciola CR. Nanostructured materials for inhibition of bacterial adhesion in orthopedic implants: a minireview. Int J Artif Organs. 2008;31(9):771-776. doi:10.1177/039139880803100904

19. Bidossi A, Bottagisio M, De Grandi R, et al. Ability of adhesion and biofilm formation of pathogens of periprosthetic joint infections on titanium-niobium nitride (TiNbN) ceramic coatings. J Orthop Surg Res. 2020 Mar 4;15(1):90. doi: 10.1186/s13018-020-01613-w.

20. Patel SS, Aruni W, Inceoglu S, et al. A comparison of Staphylococcus aureus biofilm formation on cobalt-chrome and titanium-alloy spinal implants. J Clin Neurosci. 2016;31:219-23. doi: 10.1016/j.jocn.2016.03.013.

21. Metsemakers WJ, Schmid T, Zeiter S, et al. Titanium and steel fracture fixation plates with different surface topographies: Influence on infection rate in a rabbit fracture model. Injury. 2016;47(3):633-9. doi: 10.1016/j.injury.2016.01.011.

22. Ghimire N, Pettygrove BA, Pallister KB, et al. Direct Microscopic Observation of human neutrophil-Staphylococcus aureus interaction in vitro suggests a potential mechanism for initiation of biofilm infection on an implanted medical device. Infect Immun. 2019;87:e00745-19. doi: 10.1128/IAI.00745-19

This article is protected by copyright. All rights reserved. 
23. Pensyan A, Nagy SS, Kjelleberg S, et al. Rapid microevolution of biofilm cells in response to antibiotics. NPJ Biofilms Microbiomes. 2019;6;5:34. doi: 10.1038/s41522-019-0108-3.

24. Rachid S, Ohlsen K, Wlfgang W, et al. Effect of Subinhibitory Antibiotic Concentrations on Polysaccharide Intercellular Adhesin expression in biofilmforming Staphylococcus epidermidis. Antimicrob Agents Chemother. 2000;44(12):3357-63. doi: 10.1128/aac.44.12.3357-3363.2000.

25. Gupta TT, Gupta NK, Pestrak MJ, et al. Investigation of Staphylococcus aureus aggregates on orthopedic materials under varying shear stress. Appl Environ Microbiol. 2020;AEM.01234-20. doi: 10.1128/AEM.01234-20.

26. Bidossi A, Bottagisio M, Savadori $\mathrm{P}$, et al. Identification and Characterization of Planktonic Biofilm-Like Aggregates in Infected Synovial Fluids From Joint Infections. Front Microbiol. 2020; 0;11:1368. doi: 10.3389/fmicb.2020.01368

\section{Table}

Table 1. Bacterial adhesion on rods surfaces according to material composition

Design 1

\begin{tabular}{|c|c|c|c|}
\hline & & $\mathrm{Ti}$ & $\mathrm{CoCr}$ \\
\hline \multirow{3}{*}{ S. aureus } & Notch & $\mathrm{ns}$ & ns \\
\hline & Rod & $\mathrm{ns}$ & ns \\
\hline & Cut & $\mathrm{ns}$ & $* * *$ \\
\hline \multirow{3}{*}{ S. epidermidis } & Notch & $\mathrm{ns}$ & ns \\
\hline & Rod & $\mathrm{ns}$ & $* * *$ \\
\hline & Cut & $\mathrm{ns}$ & $* * *$ \\
\hline P. aeruginosa & Notch & $\mathrm{ns}$ & ns \\
\hline
\end{tabular}

This article is protected by copyright. All rights reserved. 


\begin{tabular}{|c|c|c|c|}
\hline & Rod & $\mathrm{ns}$ & ns \\
\hline & Cut & $\mathrm{ns}$ & ns \\
\hline & \multicolumn{3}{|c|}{ Design 2} \\
\hline & & $\mathrm{Ti}$ & $\mathrm{CoCr}$ \\
\hline \multirow{3}{*}{ S. aureus } & Round rod & ns & $* *$ \\
\hline & Flat rod & ns & $*$ \\
\hline & Cut & ns & $* * *$ \\
\hline \multirow{3}{*}{ S. epidermidis } & Round rod & $\mathrm{ns}$ & $* *$ \\
\hline & Flat rod & ns & ns \\
\hline & Cut & ns & $* * *$ \\
\hline \multirow{3}{*}{ P. aeruginosa } & Round rod & ns & ns \\
\hline & Flat rod & ns & ns \\
\hline & Cut & ns & $* * *$ \\
\hline
\end{tabular}

Ti, titanium alloy; CoCr, cobalt chromium alloy; ns, not significant; $*=p<0.05$;

$* *=\mathrm{p}<0.01 ; * * *=\mathrm{p}<0.001$

This article is protected by copyright. All rights reserved. 


\section{Figures}

Fig 1 S. aureus
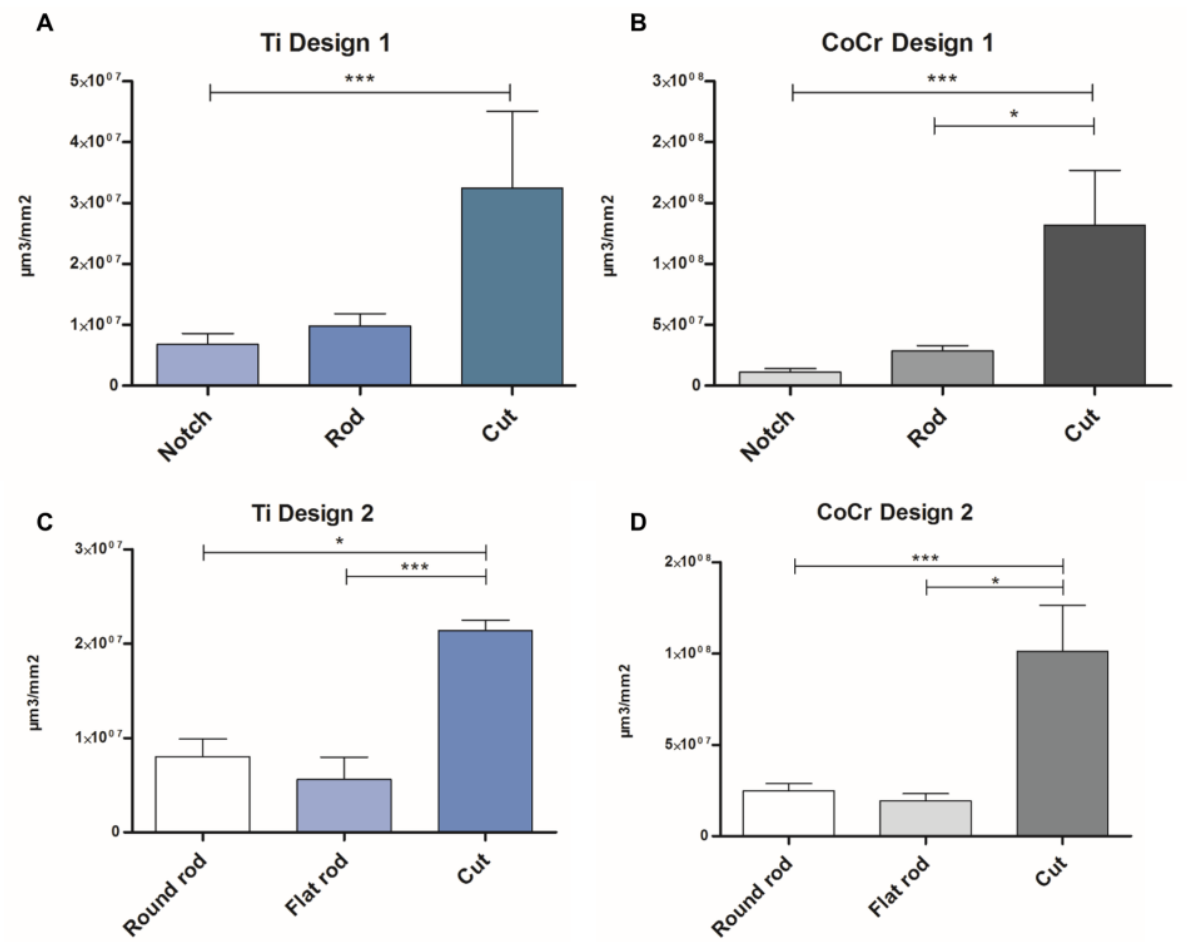

Figure 1. S. aureus biofilm formation on different areas of spinal instrumentation. Biofilm biomass was assessed by means of CLSM and was expressed as volume/surface ratio. Panel A, titanium alloy design 1 rod; panel $\mathrm{B}$, cobalt chromium alloy design 1 rod; panel $\mathrm{C}$ titanium alloy design 2 rod; panel $\mathrm{D}$, cobalt chromium alloy design 2 rod. $\mathrm{P}$ value, ${ }^{*}=\mathrm{p}<0.05 ; * *=\mathrm{p}<0.01 ; * * *=\mathrm{p}<0.001$.

This article is protected by copyright. All rights reserved. 

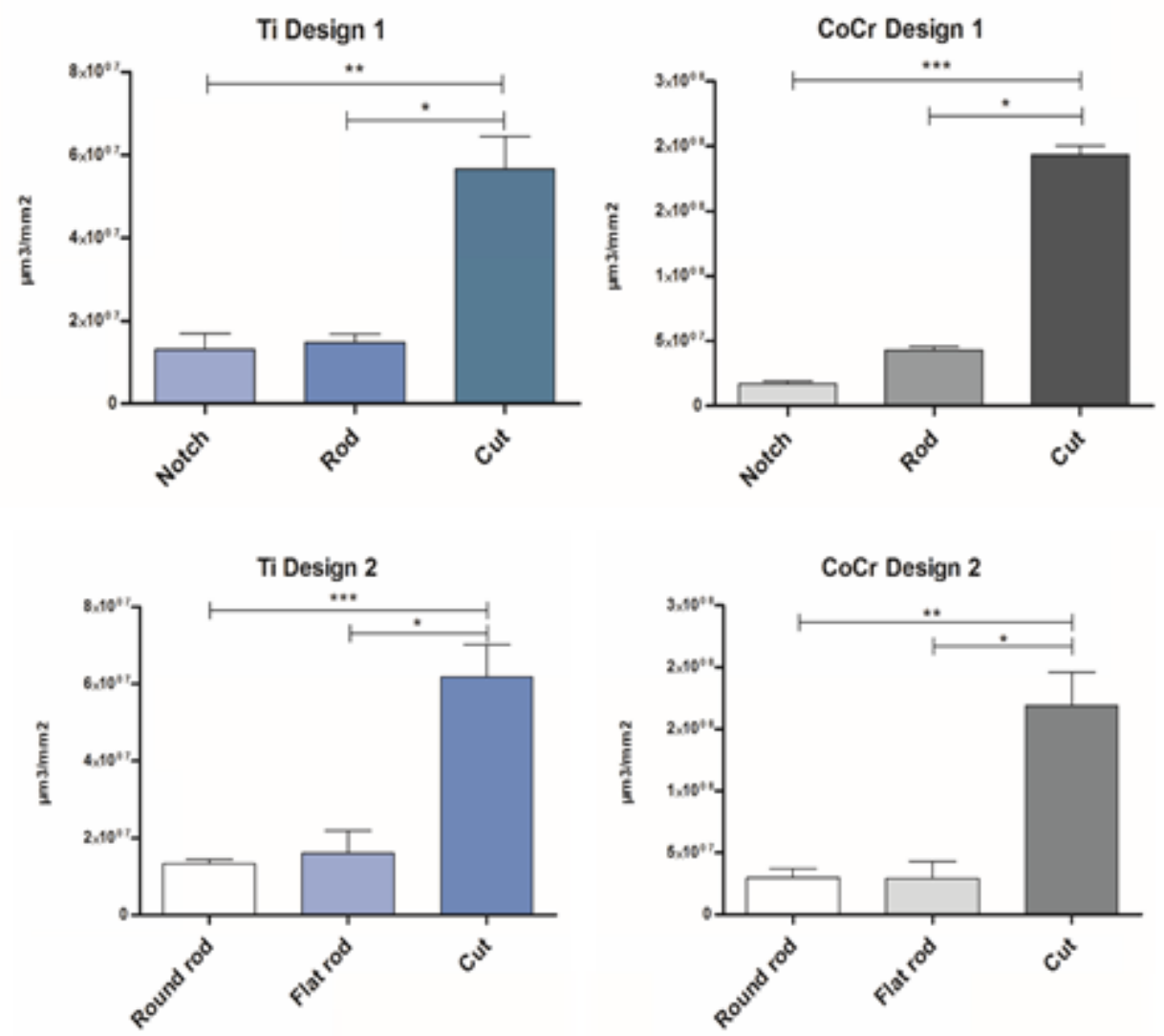

Figure 2. S. epidermidis biofilm formation on different areas of spinal instrumentation. Biofilm biomass was assessed by means of CLSM and was expressed as volume/surface ratio. Panel A, titanium alloy design 1 rod; panel $\mathrm{B}$, cobalt chromium alloy design 1 rod; panel $\mathrm{C}$ titanium alloy design 2 rod; panel $\mathrm{D}$, cobalt chromium alloy design 2 rod. $\mathrm{P}$ value, $*=\mathrm{p}<0.05 ; * *=\mathrm{p}<0.01 ; * * *=\mathrm{p}<0.001$. 

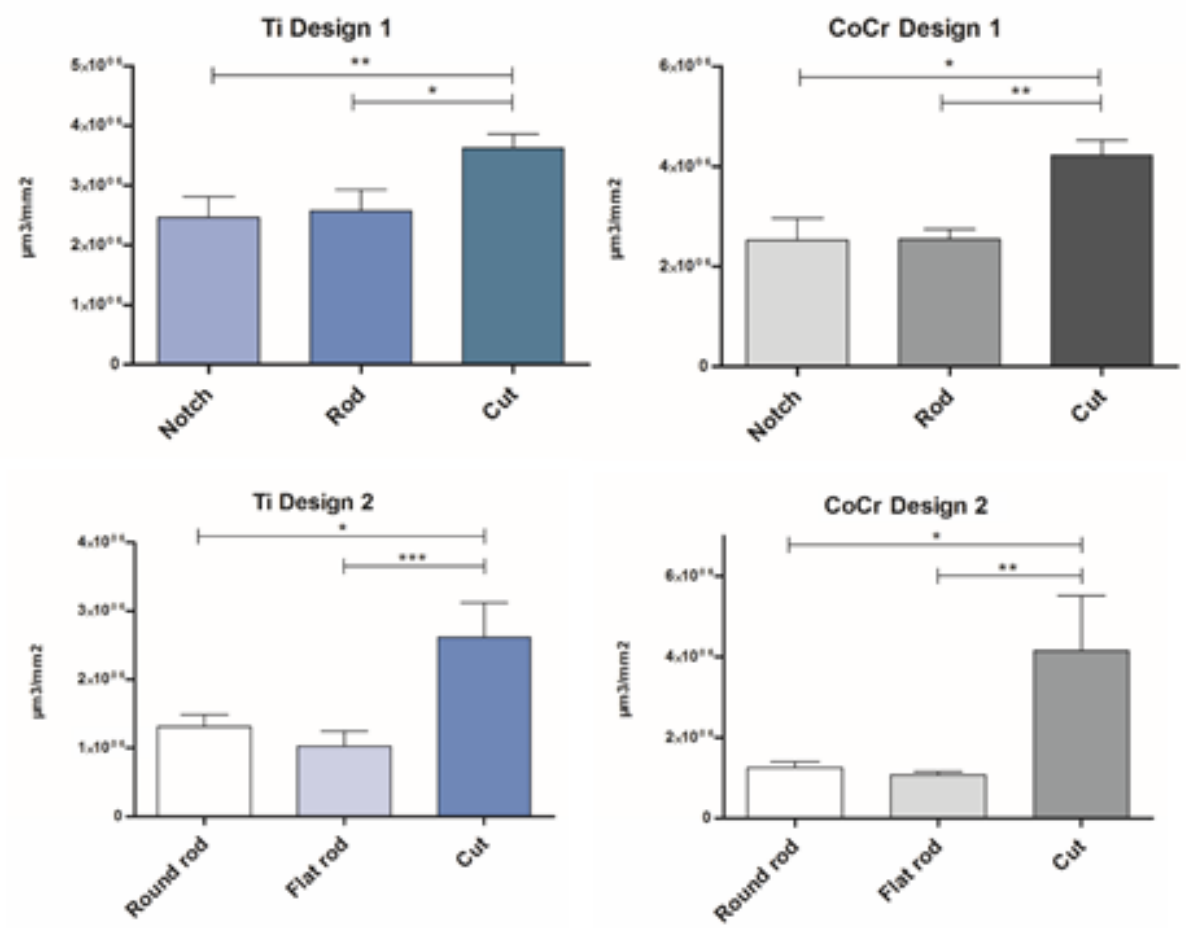

Figure $3 P$. aeruginosa biofilm formation on different areas of spinal instrumentation. Biofilm biomass was assessed by means of CLSM and was expressed as volume/surface ratio. Panel A, titanium alloy design 1 rod; panel B, cobalt chromium alloy design 1 rod; panel $\mathrm{C}$ titanium alloy design 2 rod; panel $\mathrm{D}$, cobalt chromium alloy design 2 rod. $\mathrm{P}$ value, $*=\mathrm{p}<0.05 ; * *=\mathrm{p}<0.01 ; * * *=\mathrm{p}<0.001$.

This article is protected by copyright. All rights reserved. 


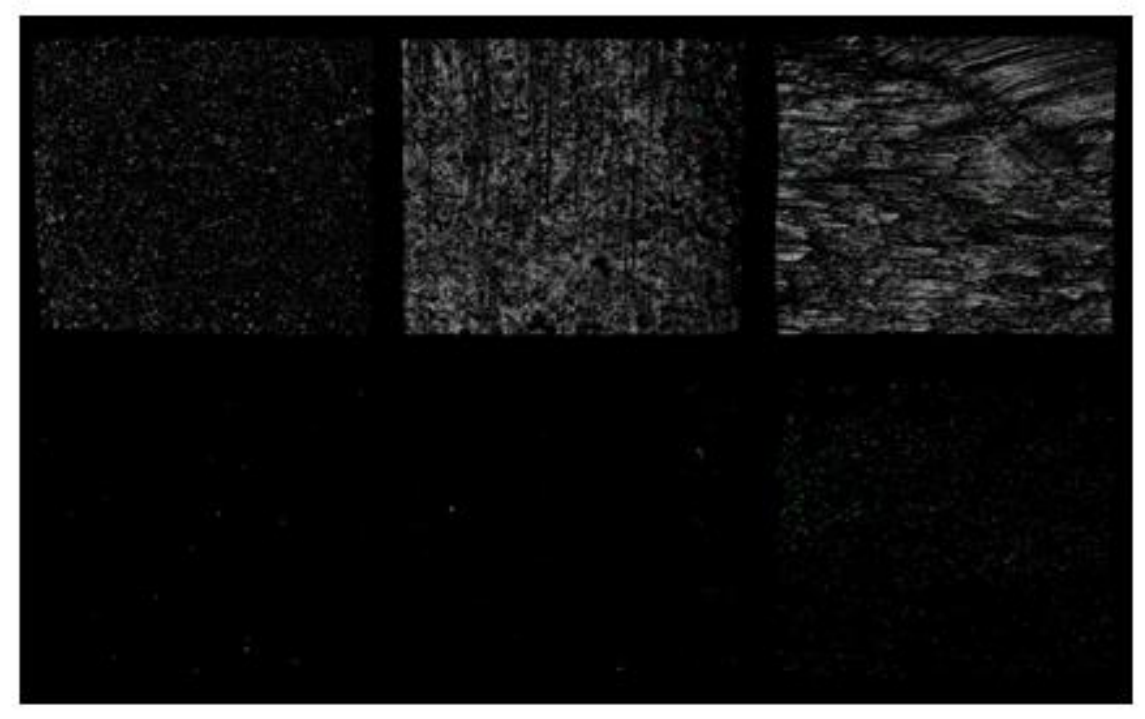

Figure 4. CLSM 3D representation of biofilm formation on different surfaces. In the upper panels, rod surface is represented in gray and cells are represented in green. In the lower panels surface was omitted to highlight bacterial biofilm microcolonies. The surface was detected by reflected imaging, while cells were stained with Syto®9. Each picture represents an area of $531 \times 531 \mu \mathrm{m}$.
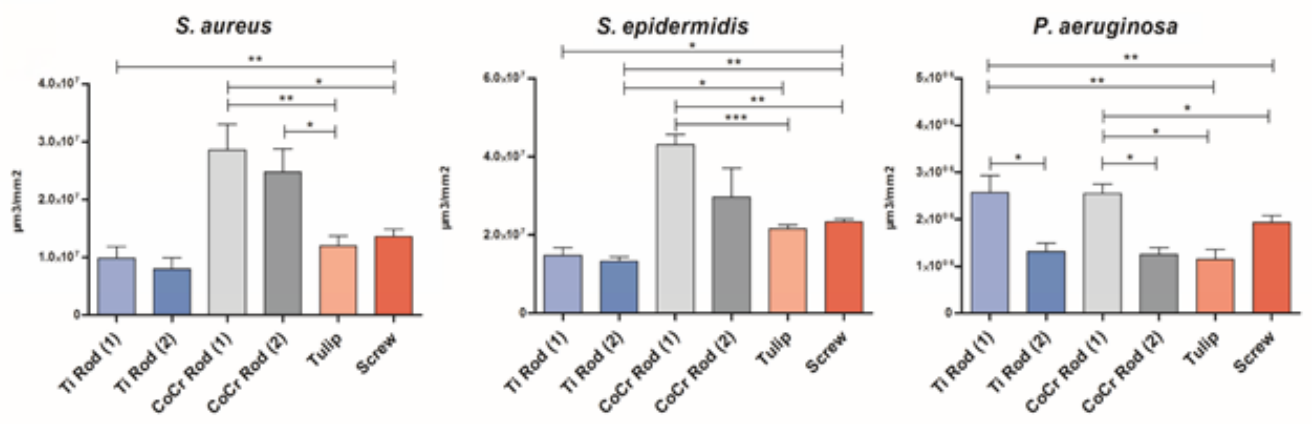

Figure 5. Comparison of biofilm formation between rods, tulips and screws. Biofilm biomass was assessed by means of CLSM and was expressed as volume/surface ratio. Panel A, S. aureus; panel B, S. epidermidis; panel C, P. aeruginosa. P value, $*=\mathrm{p}<0.05 ; * *=\mathrm{p}<0.01 ; * * *=\mathrm{p}<0.001$ 